www.periodicos.unimontes.br/index.php/caminhosdahistoria

\title{
DA UTILIDADE DA CIÊNCIA: A FEBRE AMARELA NOS DEBATES DA SOCIEDADE DE MEDICINA E CIRURGIA DE JUIZ DE FORA NO INÍCIO DO SÉCULO XX
}

Vanessa Lana ${ }^{1}$

Recebido em: 23/04/2020

Aprovado em: 10/06/2020

Resumo: O presente texto analisa os debates sobre as controvérsias em torno das formas de transmissão da febre amarela que envolveram a elaboração de um plano de defesa sanitária pelos médicos da Sociedade de Medicina e Cirurgia de Juiz de Fora (SMCJF) no início do século XX. A Instituição foi fundada em 20 de outubro de 1889 e se constituiu num espaço de integração e defesa dos interesses profissionais, debatendo problemas sanitários locais e questões de ordem médica em pauta nos cenários científicos nacional e internacional. As associações médicas fundadas no Brasil em fins do século XIX estiveram pautadas em questões científicas, corporativas e políticas, atuando tanto na defesa dos interesses profissionais dos associados quanto na busca do monopólio da função de consultores do Estado em relação à saúde. A elaboração e divulgação dos planos de intervenção, aqui analisada a partir dos estatutos e boletins da instituição, foi uma das principais estratégias utilizadas pelo corpo societário para legitimar sua categoria profissional e obter prestígio e reconhecimento perante seus pares, a municipalidade e os poderes públicos.

Palavras-chave: História das Ciências; Associativismo Científico; Academias e Instituições; Sociedade de Medicina e Cirurgia; Febre Amarela.

\section{DE LA UTILIDAD DE LA CIENCIA: FIEBRE AMARILLA EN LAS DISCUSIONES DE LA SOCIEDAD DE MEDICINA Y CIRUGÍA DE JUIZ DE FORA EN EL PRINCIPIOS DEL SIGLO XX}

Resumen: Este texto analiza los debates sobre las controversias en torno a las formas de transmisión de la fiebre amarilla que involucraron la elaboración de un plan de defensa sanitaria por parte de los médicos de la Sociedad de Medicina y Cirugía de Juiz de Fora (SMCJF) a principios del siglo XX. La Institución fue fundada el 20 de octubre de 1889 y constituyó un espacio para la integración y defensa de los intereses profesionales, debatiendo los problemas locales de salud y los problemas médicos en la escena científica nacional e internacional. Las asociaciones médicas fundadas en Brasil a fines del siglo XIX se guiaron por cuestiones científicas, corporativas y políticas, actuando tanto en defensa de los intereses profesionales de los miembros como en la búsqueda del monopolio del papel de los consultores estatales en relación con la salud. La elaboración y difusión de los planes de intervención, analizados aquí a partir de los estatutos y boletines de la institución, fue una de las principales estrategias utilizadas por el organismo corporativo para legitimar su categoría

\footnotetext{
${ }^{1}$ Doutora em História das Ciências. Pós-Doutorado pela Casa de Oswaldo Cruz/FIOCRUZ. Professora do Departamento de História da Universidade Federal de Viçosa e do Mestrado em Patrimônio Cultural, Paisagens e Cidadania. E-mail: vanessalana@ufv.br. ORCID: https://orcid.org/0000-0002-1950-1206.
} 
profesional y obtener prestigio y reconocimiento ante sus pares, el municipio y las autoridades públicas.

Palabras clave: Historia de las ciencias; Asociaciones científicas; Academias e instituciones; Sociedad de Medicina y Cirugía; Fiebre amarilla.

\title{
ON THE UTILITY OF SCIENCE: YELLOW FEVER IN THE DISCUSSIONS OF JUIZ DE FORA'S SOCIETY OF MEDICINE AND SURGERY IN THE EARLY $20^{\text {th }}$ CENTURY
}

\begin{abstract}
This text analyzes the debates about the controversies around the ways of transmission of yellow fever that involved the elaboration of a sanitary defense plan by the doctors of the Society of Medicine and Surgery of Juiz de Fora (SMCJF) in the beginning of the 20th century. The Institution was founded on October 20, 1889 and constituted a space for integration and defense of professional interests, debating local health problems and medical issues on the national and international scientific scene. Medical associations founded in Brazil at the end of the 19th century were guided by scientific, corporate and political issues, acting both in defense of the professional interests of members and in the search for a monopoly of the role of State consultants in relation to health. The elaboration and dissemination of the intervention plans, analyzed here from the institution's statutes and bulletins, was one of the main strategies used by the corporate body to legitimize their professional category and obtain prestige and recognition before their peers, the municipality and the public authorities.
\end{abstract}

Keywords: History of Sciences; Scientific Associations; Academies and Institutions; Society of Medicine and Surgery; Yellow Fever.

A febre amarela é uma doença infecciosa não-contagiosa causada por vírus e transmitida por mosquitos em áreas urbanas ou silvestres. Sob o ponto de vista epidemiológico divide-se a doença em duas formas, rural e urbana, que diferem entre si quanto à natureza dos transmissores e hospedeiros vertebrados e o local de ocorrência. No ciclo silvestre, em áreas florestais, o vetor é principalmente o mosquito Haemagogus, e no meio urbano, o Aedes aegypti (VASCONCELOS, 2003). Nos dias atuais, a identificação e os modos de transmissão da febre amarela são consensos entre os profissionais da saúde. Todavia, por longos períodos, a transmissibilidade e as medidas profiláticas contra a doença impulsionaram fortes debates no interior da comunidade científica.

No presente texto, analisaremos as controvérsias ${ }^{2}$ em torno das formas de transmissão da febre amarela que envolveram a elaboração de um plano de defesa sanitária debatido pelos médicos da Sociedade de Medicina e Cirurgia de Juiz de Fora (SMCJF) no início do século XX. A SMCJF foi fundada em 20 de outubro de 1889, constituindo-se num espaço de integração e fortalecimento do campo médico, desempenhando importante papel na defesa dos interesses profissionais da categoria. Nas reuniões da Sociedade estiveram em pauta

\footnotetext{
${ }^{2}$ Há uma ampla literatura sobre controvérsias científicas e contextos sociais. Para a discussão sobre contextos científicos e sociais e a implementação de modelos de organização do trabalho médico, ver: LANA, 2017.
} 
debates acerca dos problemas sanitários locais e discussões biomédicas com questões presentes nos principais círculos científicos nacionais e estrangeiros. As principais fontes para construção desse trabalho foram os Estatutos e Boletins com as atas das reuniões da SMCJF e jornais do período.

Várias enfermidades foram objeto de discussão nas sessões da Instituição, como, por exemplo, a varíola, a sífilis, o cólera, o beribéri, a malária, dentre outras. Mas de todas as doenças discutidas, nenhuma demandou tantas atenções e preocupações como a febre amarela. Sobre esta, travou-se um amplo debate em torno de sua etiologia e propagação, na preocupação dos médicos em impedir que uma epidemia amarílica assolasse o município, como já vinha ocorrendo com localidades vizinhas. A possibilidade do surgimento de uma epidemia de febre amarela em Juiz de Fora fomentou o desenvolvimento de um plano de defesa sanitária nos primeiros anos dos novecentos para envio ao governo mineiro, visando impedir a deflagração da enfermidade.

Este trabalho insere-se no campo de pesquisas sobre a institucionalização da ciência no Brasil, atentando à relação entre o processo de institucionalização e as condições sociais, políticas e econômicas locais. Entendemos a atuação da ciência como instituição social que tem apoio num conjunto de valores que normatizam e regularizam as práticas e comportamentos de seus membros ou praticantes. Nesse sentido, compreendemos o processo de institucionalização como o de implantação, desenvolvimento e consolidação de atividades científicas num determinado tempo histórico (FIGUEIRÔA, 1997).

Ao analisarmos a atuação e intervenção da instituição nas questões de saúde do município, temos como pano de fundo a questão do utilitarismo científico. O interesse pela aplicabilidade e utilidade da ciência esteve presente nas Sociedades científicas até as primeiras décadas do século XX. Ressaltava-se o componente utilitarista da ciência, colocando-a a serviço do progresso e da transformação do país (CAPEL, 1992). A prática científica era encarada como importante agente de atuação para desenvolvimento e melhoria do espaço e vida das populações. Assim, os fins utilitários promovidos pela ciência mobilizariam a sociedade mais ampla a valorizar a atividade científica e dariam maior visibilidade à atuação dos profissionais ligados à ciência e das postulações por estes defendidas e empregadas.

Para discutir os pontos acima apresentados, o texto está dividido em três partes. Na primeira, apresentaremos os atores e o cenário das discussões: a SMCJF. Na segunda, nos voltaremos para as principais teorias explicativas sobre a transmissão da febre amarela, contextualizando o cenário das discussões na instituição. E, em seguida, analisaremos a 
discussão do corpo societário da SMCJF, destacando os debates sobre as condições de salubridade locais que envolveram a elaboração do plano de defesa sanitária.

\section{Os atores em cena: a Sociedade de Medicina e Cirurgia de Juiz de Fora}

As sociedades médicas brasileiras surgiram no século XIX, num momento de expansão da medicina no país. A filiação a estas agremiações significava um passaporte para a alta posição social da categoria: a elite médica. Ser associado indicava a integração a um estrato superior da hierarquia social da medicina (FERREIRA; MAIO; AZEVEDO, 1998). Esses espaços institucionais tiveram sua atuação pautada em aspectos da organização da profissão médica, na defesa dos interesses corporativos destes profissionais e também atuando como consultores e assessores do Estado em assuntos relativos à saúde pública, principalmente em períodos de surtos epidêmicos.

A primeira sociedade médica fundada no Brasil foi a Sociedade de Medicina do Rio de Janeiro (SMRJ) em 1829, transformando-se em Academia Imperial de Medicina (AIM) logo depois, em 1835. Em 1886 foi fundada outra sociedade médica no Rio de Janeiro, a Sociedade de Medicina e Cirurgia do Rio de Janeiro (SMCRJ). A SMCRJ contrastou de sua antecessora pela autonomia frente ao poder público. Juntamente com os periódicos Brasil Médico (RJ) e Gazeta Médica da Bahia atuou na modernização científica e institucional da medicina brasileira, através da organização dos primeiros congressos médicos no país (Ferreira, Maio e Azevedo, 1998). Na década de 1890, foi fundada a Sociedade de Medicina e Cirurgia de São Paulo (SMCSP), que agregava a elite profissional da região, constituindo-se no principal espaço de discussões médicas no período antecedente ao surgimento da Faculdade de Medicina na capital paulista em 1913 (TEIXEIRA, 2007). De modo geral, essas associações tiveram uma ação plural, em diferentes instâncias, com múltiplos objetivos, atividades e funções. As ações pautaram-se em questões científicas, corporativas e políticas, objetivando tanto a defesa dos interesses profissionais dos associados quanto o monopólio da função de consultores do Estado em relação à saúde pública.

A Sociedade de Medicina e Cirurgia de Juiz de Fora foi fundada em 20 de outubro de 1889, em sessão solene no Salão Nobre da Câmara Municipal da cidade mineira. Juiz de Fora, palco da associação, teve sua emancipação, na condição de vila, em 1850. Já na segunda metade do século XIX, assistiu a um grande crescimento econômico, fruto da dinamização da produção cafeeira ocorrida, principalmente, após a construção da Rodovia União e Indústria. A Rodovia, construída em 1861, ligava Juiz de Fora a Petrópolis e foi uma das principais vias 
de escoamento da produção cafeeira em Minas Gerais. Tal dinamismo econômico foi ainda mais intensificado com a inauguração da Estrada de Ferro D. Pedro II em 1875, que intensificou o ciclo de produção e facilitou o escoamento do café (MIRANDA, 1990). O período também foi de diversificação das atividades econômicas. Os capitais excedentes da produção cafeeira foram, em grande parte, aplicados no setor industrial, sobretudo têxtil e alimentício, e na construção civil. A partir de 1890 já era possível perceber um aumento do peso da atividade industrial sobre o conjunto da produção e economia locais (GIROLETTI, 1988).

A organização da SMCJF fez parte do aparato institucional que estava sendo montado na cidade, sendo um ícone da modernização, no campo da saúde. No período da "belleépoque" juizforana outros ícones de modernidade identificados pela literatura foram: o Banco de Crédito Real (1889), no sistema bancário; a Rodovia União e Indústria (1861) e a Estrada de Ferro D. Pedro II (1975), no ramo de transporte; a Companhia Mineira de Eletricidade, no fornecimento de energia e, no âmbito da educação, o Instituto Grambery (1890) e a Academia de Comércio (1894) (Christo, 1994).

Os estatutos da SMCJF elucidavam o caráter corporativo da instituição, de sua atuação na defesa dos interesses profissionais e na projeção da importância da figura do médico para a sociedade:

\footnotetext{
"Dos fins da Sociedade".

(...) $\S 4^{\circ}$ Defender os interesses da classe medica e das outras a que pertencerem os seus membros. (Estatutos da SMCJF, 1890).

"Dos fins e constituições de Sociedade".

(...) $4^{\circ}$ Defender os interesses da classe medica e das classes acessórias que tiverem representantes na Sociedade (ESTATUTOS da SMCJF, 1890, p. 2).
}

A defesa dos interesses profissionais se daria, em muitos momentos, através de estratégias que visavam legitimar as práticas e evidenciar a utilidade e necessidade dos conhecimentos perante a opinião pública. A atuação da associação estaria voltada para angariar espaços para o conhecimento e a prática que produziam e contribuir para a construção da imagem do médico como o único agente apto e qualificado ao exercício de curar. E, nesse sentido, conferir à SMCJF o posto de espaço legítimo de postulação de normas e medidas de higiene e saneamento a serem postas em prática pela municipalidade (Lana e Teixeira, 2008).

Nos estatutos da Sociedade é possível verificar também o interesse dos associados em questões relacionadas às melhorias sanitárias e estudos que visassem conter ou amenizar as “(...) causas permanentes ou transitórias de insalubridade da cidade de Juiz de Fora e seu 
município, ou de qualquer outra localidade (...)" (ESTATUTOS da SMCJF, 1890, p. 4). Essa frente de atuação da instituição ia ao encontro do cenário e das mudanças na dinâmica urbana juizforana de fins do século XIX e início do XX, marcada por um intenso processo de urbanização que trazia consigo uma série de problemas socioeconômicos. Os novos afluxos populacionais que se direcionavam para o município, assim como os altos índices de crescimento do número de habitantes desembocavam em novos desequilíbrios e deficiências urbanas. Tais questões estiveram diretamente ligadas à insuficiência na oferta de serviços públicos básicos e de empregos. Intensificavam-se os problemas de infraestrutura, tais como as deficiências sanitárias, nos sistemas de esgoto e de abastecimento de água, e a consequente proliferação de doenças e epidemias (MIRANDA, 1990).

$\mathrm{Na}$ inauguração da Instituição, o então presidente identificou a SMCJF como "guarda avançada da salubridade pública" (BOLETIM da SMCJF - Ata da inauguração, 1889, p. 2). Nesse posto, a instituição se constituiu como o espaço, por excelência, das discussões médicocientíficas e da tentativa de legitimação da categoria profissional como a única habilitada para o exercício de curar.

A fundação da Sociedade de Medicina e Cirurgia de Juiz de Fora portanto, refletiu o anseio da categoria médica local em angariar espaços para a ciência que produziam. Através da atuação enquanto membros da instituição, a categoria médica juizforana buscou evidenciar a utilidade e aplicabilidade de seu ofício à municipalidade e à sociedade em geral, ressaltando a importância da figura do médico e de seus conhecimentos específicos para o bem-estar e a salubridade pública. A principal estratégia da qual os associados lançaram mão, visando alcançar os objetivos acima descritos, foi a elaboração de propostas de higiene e saneamento, endereçadas tanto à população juizforana como aos poderes públicos locais (LANA, 2006). Tais propostas estiveram embasadas pelo discurso médico-higiênico, voltando-se para os hábitos individuais e pareceres sobre questões de interesse público, como higiene e aspectos relacionados ao espaço urbano, como nas discussões que envolveram a ocorrência da febre amarela no município. Mas antes de analisarmos essas discussões, vamos percorrer as explicações sobre a doença e suas formas de transmissão ao longo da história.

\section{Miasmas ou bacteriologia?}

Até as últimas décadas do século XIX a comunidade científica identificava a febre amarela como uma doença que se originava de emanações pútridas, os miasmas. A "teoria miasmática", de modo geral, defendia a transmissão das doenças através de miasmas, ou seja, 
eflúvios resultantes de matéria orgânica em decomposição, fruto de condições ambientais específicas. As epidemias de doenças infecciosas estariam relacionadas ao estado da atmosfera e aspectos do meio ambiente. Dessa forma, as medidas de combate a epidemias incluíam, basicamente, a reforme sanitária e das condições de higiene (ACKERKNECHT, 1948). Elementos do cotidiano, dentro dessa perspectiva, representavam ameaças à salubridade das cidades. A água, por exemplo, necessitava estar em movimento para impedir a formação dos miasmas. A estagnação e as aglomerações de modo geral eram objeto de preocupação para os higienistas.

Havia divergências acerca dos meios de propagação da febre amarela, se seria um mal contagioso ou uma doença transmissível, infecciosa. Em linhas gerais, a noção de contágio está associada à possibilidade da transmissão de doenças diretamente de pessoa a pessoa, ou indiretamente, pelo ar, água, seres vivos e outros objetos contaminados. Já a infecção seria a invasão do corpo por germes que se reproduzem e multiplicam causando doenças. Esses microrganismos necessitariam de um agente que o transportasse do doente a uma pessoa sã (PELLING, 1993).

Os anticontagionistas sugeriam medidas de caráter local, ações sobre as condições sociais e ambientais geradoras dos miasmas causadores de epidemias. Pautavam-se na remoção de elementos considerados difusores de doenças, tais como lixo, esgoto, habitação sem ventilação e com superlotação (ACKERKNECHT, 1948). No caso da febre amarela, as orientações eram a circulação e canalização das águas para evitar a estagnação fluvial, o que ocasionaria casos da doença. Eram alvos das ações dos higienistas, para o combate do mal amarílico, as roupas e objetos de uso dos amarílicos, os cadáveres e os ambientes por estes frequentados. Como geralmente os maiores surtos ocorriam no verão, a febre amarela era relacionada a fatores ambientais, tendo as explicações para sua incidência diretamente ligadas ao calor, à quantidade de chuvas e à umidade proveniente dos pântanos.

Em fins do século XIX, o desenvolvimento das pesquisas e conhecimentos em microbiologia colocaria novas questões na agenda de debates sobre saúde. A partir da teoria dos germes organizou-se uma intervenção mais pontual, de certas doenças em certos indivíduos, distanciando-se da ideia de abarcar o todo. Esta ação mais pontual teve como pano de fundo o laboratório, que conferiu à saúde pública uma legitimidade diferente de ação. A supremacia laboratorial passou pela mudança na percepção da doença, a partir da associação de causalidade com um agente específico (CUNNINGNAM; WILLIANS, 1992).

No caso da febre amarela, o relativo consenso, baseado na teoria miasmática, com relação às medidas cabíveis para o combate a enfermidade deu lugar a um impasse acerca da 
profilaxia. As escolhas sobre qual o melhor método estavam condicionadas ao tipo de germe identificado como possível causador da doença, colocando na agenda diferentes ações a serem executadas, conforme o microrganismo identificado (BENCHIMOL, 2001).

O desenvolvimento das pesquisas em microbiologia no Brasil, no tocante à febre amarela, iniciaram-se com Domingos José Freire. Em dezembro de 1879, Freire, catedrático de química orgânica da Faculdade de Medicina do Rio de Janeiro, anunciou a descoberta de um microrganismo que considerava ser o causador do mal amarílico. Para combater a doença Freire indicava injeções hipodérmicas de salicitado de sódio. Nos primeiros meses de 1883, desenvolveu uma vacina contra a doença. O princípio ativo era o Cryptococcus xanthogenicus, uma planta microscópica que teve sua virulência atenuada por técnicas pasteurianas. A vacina de Freire, juntamente com a vacina antivariólica, constituíam os únicos meios profiláticos desta natureza para enfermidades humanas ${ }^{3}$. Segundo Benchimol, as pesquisas de Freire desembocaram na primeira teoria etiológica de matriz pasteuriana, para explicação da febre amarela, elaborada no Brasil (BENCHIMOL, 1999).

Outra frente de explicação foi defendida por João Batista Lacerda, médico diretor do Museu Nacional do Rio de Janeiro. Lacerda indicou outro micróbio como o verdadeiro agente da doença, o fungus febris flavae. O microrganismo era polimorfo, o que suscitou debates no ambiente científico, em virtude das discussões acerca do polimorfismo e a incompatibilidade com a especialidade etiológica e com certos procedimentos experimentais (BENCHIMOL, 2001).

Desde o início dos anos 1890 multiplicaram-se na imprensa médica e leiga do Rio de Janeiro especulações sobre o papel dos insetos na transmissão de doenças. Estes eram vistos não como hospedeiros de parasitas, mas sim como agentes mecânicos de transmissão de germes (BENCHIMOL, 2001). No alvorecer do século XX, comprovaria-se a transmissão da febre amarela por um culicidio. Tal comprovação só se tornou possível com as pesquisas do médico cubano Carlos Finlay.

A partir de 1881, Finlay começou a publicar uma série de artigos classificando o mosquito como o verdadeiro transmissor da febre amarela. A primeira comunicação da descoberta foi feita em agosto de 1881 à Real Academia de Ciências Médicas, Físicas y Naturaes de la Havana. Na conferência, Finlay pormenorizou a anatomia e hábitos do mosquito, ressaltando as condições necessárias para reprodução do culicidio e da própria doença (BENCHIMOL, 1999).

\footnotetext{
3 Sobre as repercussões e utilização da vacina de Freire na antiga Corte e biografia do cientista, ver: BENCHIMOL, 1999 e 2001.
} 
A teoria de Finlay, no entanto, não obteve aceitabilidade imediata, levando aproximadamente vinte anos para ser validada no ambiente científico. Num período em que doenças como a tuberculose, o cólera e a febre tifóide indicavam a potencialidade da transmissão hídrica e do contágio, a ideia de transmissibilidade pelo mosquito não teria obtido grande aceitabilidade. Esse quadro só de modificou quando, em 1897, o inglês Ronald Ross comprovou que o plasmódio da malária era transportado por mosquitos do gênero Anopheles, o que abriu espaço para novas pesquisas (TEIXEIRA, 2001).

Naquele contexto, Cuba, sob intervenção norte-americana com o fim da guerra hispano-americana, passava por um período de disseminação da febre amarela e aumento no número de mortes pela doença. Foi então que o governo norte-americano enviou uma comissão de saúde do Exército para analisar os aspectos da etiologia e profilaxia da enfermidade. O resultado da comissão foi a confirmação da teoria de Finlay, e, em fevereiro de 1901, ela foi apresentada ao Congresso Médico Pan-Americano realizado em Havana (TEIXEIRA, 2001).

Para Benchimol, as experiências realizadas em Cuba constituem um divisor de águas na história da febre amarela. Isto porque afastou-se da saúde pública as intermináveis querelas acerca da etiologia da doença. E, apesar de não terem sido descartados de imediato os germes já incriminados, várias ações foram viabilizadas alcançado-se certo controle das epidemias em diferentes territórios (BENCHIMOL, 2001).

No Brasil, a aceitação da teoria culicidiana e a adesão à profilaxia única, que era o extermínio do mosquito transmissor, como forma de combater a enfermidade mostrou-se mais evidente no início do século XX. O ponto alto do debate sobre a validação ou não da teoria se deu em 1903, com a realização, na cidade do Rio de Janeiro, do "V Congresso Brasileiro de Medicina e Cirurgia". O evento assinalou o cerne do confronto entre "exclusivistas", partidários da teoria havanesa e liderados pelo médico sanitarista Oswaldo Cruz; e os "não convencidos" com a descoberta de Finlay (BENCHIMOL, 2001). Os defensores da teoria culicidiana fizeram o possível para obtenção do aval da corporação médica para com a nova estratégia de intervenção no combate à febre amarela.

As discussões acerca da forma de transmissão e, consequentemente, profilaxia do mal amarílico extrapolaram as fronteiras da antiga Capital Federal ocorrendo também nas sessões da Sociedade de Medicina e Cirurgia de Juiz de Fora, particularmente nos anos de 1904 e 1905. O fomento às discussões se deu pelo crescimento da incidência da doença e de uma possível onda epidêmica no município, e também pelos anseios de controle da enfermidade e 
legitimação do papel institucional de "guarda avançada da salubridade pública", pela associação médica juizforana.

\section{A Febre Amarela nos debates da Sociedade de Medicina e Cirurgia de Juiz de Fora}

A primeira onda epidêmica de febre amarela em Juiz de Fora, que se tem registro, data de 1896. A ocorrência da doença na cidade foi relatada pelo médico Christovam em "Higiene Local"4. De acordo com Malta, três trabalhadores da Estrada de Ferro que se ocupavam em descarregar carros de carvão na estação foram vitimados e constituíram os primeiros casos da pequena epidemia que se desenvolveu nos arredores do centro urbano, só desaparecendo no ano seguinte. A enfermidade teria novamente irrompido no centro juizforano em 1899, ocasionando mais de trinta óbitos. Em 1901 teriam sido notificados novos casos da doença.

No ano de 1904, diziam os médicos da Sociedade de Medicina e Cirurgia de Juiz de Fora que não havia registros do mal amarílico na cidade. Contudo, a proximidade do verão direcionava as atenções para a possibilidade de um novo surto epidêmico. Vale destacar que naquele contexto a doença era alvo de ações coordenadas pela Diretoria Geral de Saúde Pública da capital federal que, no interior do projeto de reforma urbana do Rio de Janeiro impulsionado pelo prefeito Pereira Passos, teve como alvo três enfermidades: febre amarela, peste bulbônica e varíola. O então Diretor Geral de Saúde Pública, o médico Oswaldo Cruz liderou as ações de controle dessas doenças e teve um papel importante nas discussões em saúde naquele período. A figura do médico e seu respaldo científico serão retomados nesse texto, apontando o alinhamento, ou a busca desse alinhamento, do corpo societário da SMCJF aos preceitos e ações em ciência no país.

Na primeira sessão extraordinária da SMCJF em 1904, Christovam Malta propunha que a Sociedade:

(...) formule um plano de defesa sanitária do Estado contra a possível invasão da febre amarella, de conformidade com a moderna theoria havaneza, indicando ao governo estadual os meios actualmente aconselhados (telas preservadoras contra as picadas dos stegomyas, extinção dos culicidios, hoje considerados como os únicos vectores da febre amarella, etc.) (BOLETINS da SMCJF, 1904: 4).

A proposta foi aceita sem grandes ressalvas, e, pelo adiantado da hora, maiores discussões foram transferidas para a próxima sessão. Nas palavras de Malta ficava explícita a

\footnotetext{
4 "Higiene Local" é uma coletânea de artigos publicados no Jornal do Commercio, em fins do século XIX, e agrupados por Christovam Malta no ano de 1901. Esta coletânea foi posteriormente reunida em um livreto intitulado "Juiz de Fora no século XIX", que contém, além da parte de higiene, sessões de economia, política, demografia, educação, dentre outros.
} 
preocupação com um possível surto da doença e, principalmente o alinhamento do proponente às novas pesquisas da teoria culicidiana já ressaltadas anteriormente. A formulação de tal plano se justificava dentro dos intuitos da Instituição de atuar para o bem-estar geral da população, evidenciando a utilidade e aplicação dos seus conhecimentos. Além disso, o assessoramento ao poder público possibilitaria uma maior projeção e afirmação da atuação dos médicos associados, e a possibilidade de garantir a ordem social pela contenção de uma possível onda epidêmica.

Nos dias que se seguiram à proposta de Christovam Malta, algumas controvérsias sobre a melhor proposição das atividades preventivas tomaram contorno nas reuniões da associação. Na sessão seguinte à proposta de Malta, o médico Ambrósio Braga levantava novamente o tema da elaboração do plano de defesa sanitária, sugerindo que este fosse redigido pelo próprio Malta, visto ter sido ele o autor da proposta (BOLETINS da SMCJF, 1904).

Na sessão ordinária do dia 06 de fevereiro de 1904, os debates acerca da questão ganharam maior impulso. Malta tomou a palavra e dissertou acerca da elaboração do plano de defesa sob os moldes havaneses. Para o médico, a teoria culicidiana, da transmissão pelo mosquito, teria colocado por terra os antigos processos de desinfecção pelo ácido fênico, o formal e, ainda, destruído as doutrinas que atribuíam a propagação da moléstia ora às oscilações do lençol d'água subterrâneo, ora às correntes atmosféricas, ora à ingestão de água. Dessa forma, a profilaxia da febre amarela consistiria prioritariamente na caça aos mosquitos, desinfecção das casas e isolamento do doente ao ataque dos insetos (BOLETINS da SMCJF, 1904).

As medidas profiláticas defendidas por Malta fora questionadas por Ambrósio Braga que as considerou não eficazes e impraticáveis. Braga argumentou que admitia o papel do mosquito como vetor da doença, mas avaliava como exagerada a teoria havanesa, uma vez que tinha dúvidas de que os culicidios não podiam se infectar em outro local que não o doente ou cadáver vitimado pela febre amarela. Nesse sentido, questionava as medidas voltadas quase exclusivamente para o combate ao mosquito. $\mathrm{O}$ questionamento apresentado não indicava uma contestação direta à transmissão culicidiana da febre amarela. O que era levantado pelo médico estava relacionado às medidas profiláticas que deveriam ser tomadas. Neste ponto, Braga mostrava-se receoso da eficácia da profilaxia única, através do extermínio do mosquito. $\mathrm{O}$ argumento era de que, como condições ambientais poderiam favorecer o surgimento e desenvolvimento de novas larvas, seria cabível a indicação de outras medidas 
para controle da enfermidade, considerando não ser possível a completa extinção dos mosquitos (BOLETINS da SMCJF, 1904).

Nas palavras do médico:

\begin{abstract}
A vehiculação da febre amarella pelo stegomya rajado é hoje um facto adquirido pela sciencia, seu espírito já rendeu-se a esta verdade - mas será o stegomya o único vetor? Desaparecido o ultimo caso de febre amarella da superfície da terra, extincto o ultimo stegomya infeccionado não se poderá reproduzir esse morbo, dadas as condições meteorológicas e telluricas do clima tropical, que determinaram o primeiro caso? (...) o que quizera saber é si no laboratório da natureza tropical, onde se engendrou o gérmen que infeccionou o primeiro mosquito ou o primeiro amarellento, não se poderá repetir a confecção do terrível veneno (BOLETINS da SMCJF, 1904, p. 15).
\end{abstract}

No trecho acima podemos perceber um consenso sobre a etiologia de febre amarela, com a aceitação da teoria havaneza na explicação da propagação da doença. $O$ questionamento apontado versava sobre a forma de atuação para combater a propagação da enfermidade. Ou seja, se o combate deveria ser voltado apenas para o extermínio do mosquito ou se outras medidas de caráter sanitário deveriam ser incluídas no plano de defesa.

Os embates e questionamentos acima representam o que a literatura denomina "contagionismo contingente". O "contagionismo limitado" ou "contigente" seria um meio termo nas concepções contagionista e anticontogionista, anteriormente apresentadas. Nessa concepção, admitia-se que doenças contagiosas provinham de agentes contagiosos que, por sua vez, só agiam em conjunto com outros elementos, tais como atmosfera e fatores sociais. Assim sendo, as medidas a serem tomadas para evitar ou combater uma onda epidêmica não teriam uma homogeneidade. Ou seja, faria-se uma profilaxia mista, tentando abarcar as múltiplas possibilidades de disseminação de determinada doença (ROSEN, 1994).

Mas mesmo nesse preceito e possibilidade do "contagionismo contingente", as posições majoritárias verificadas nas falas do corpo societário da SMCJF apontavam para medidas de caráter único, exclusivamente voltadas para o extermínio do vetor, no caso o mosquito. Eduardo de Menezes, então secretário da associação, reiterava essa posição afirmando que:

(...) na theoria culicidiea da febre amarella estão provadas à sociedade as condições fundamentaes ou essenciaes, por provas experimentias e provas hygienicas, isto é, que a moléstia não se propaga pelos excreta, que ella só se propaga pelo stegomya fasciata, que preservados os doentes da sucção do mosquito a moléstia não se propaga (...) (BOLETINS da SMCJF, 1904, p. 17). 
No mesmo pronunciamento, Eduardo de Menezes destacou ainda a importância dos trabalhos da comissão então nomeada pela Sociedade para formular o plano higiênico a ser apresentado ao Governo do Estado de Minas Gerais. A comissão, organizada na mesma reunião em que Eduardo de Menezes se posicionou sobre a importância da atenção ao vetor da febre amarela como estratégia de combate, estava composta pelos médicos: Duarte de Abreu, Christovam Malta e José Nava. No discurso que ratificava a composição da comissão, o presidente da reunião salientava para que não fossem propostas medidas como a desinfecção das excretas dos doentes e nem dos objetos por eles manuseados. Isto porque, já estaria comprovado que tais elementos não eram contagiosos. Indo de encontro à posição de Ambrósio Braga findava o discurso afirmando que a adoção de um plano de profilaxia mista significaria tibieza de opinião sobre os princípios científicos já suficientemente provados e contra-provados (BOLETINS da SMCJF, 1904).

É interessante observar a preocupação destes profissionais com as "novas" descobertas da ciência, e, ao mesmo tempo, o receio em ir contra algum postulado da "ciência moderna". A teoria de Finlay, por ter sido comprovada e veiculada internacionalmente, e estar em conformidade com as novas pesquisas em microbiologia, era considerada de caráter incontestável e as medidas a serem propostas no plano de defesa sanitária deveriam seguir, incontestavelmente, os preceitos havaneses. As discussões que precederam a apresentação do plano e todas as ressalvas feitas à comissão versaram em torno da excelência da profilaxia única para conter a invasão dos mosquitos na cidade. Por se tratar de uma teoria comprovada e aceita no cenário científico, foi adotada como diretriz norteadora para impedir a deflagração de uma onda amarílica em Juiz de Fora.

A apresentação e discussão do plano de defesa sanitária ocorreu na sessão extraordinária de 27 de fevereiro de 1904. Na reunião, a primeira parte da ordem do dia esteve reservada à apresentação e discussão de alguns casos clínicos vivenciados pelos sócios. Em seguida, o médico Duarte de Abreu procedeu à leitura do relatório que seria apresentado em nome da Sociedade de Medicina e Cirurgia de Juiz de Fora ao Governo do Estado de Minas Gerais.

O discurso foi aberto com um pequeno texto que reproduz o ideário científico descrito nos parágrafos anteriores:

A conformidade do juízo das pessoas competentes com o juízo que nós mesmos formamos sobre uma idéa ou theoria, é um dos criterios mais seguros para o discernimento da verdade.

Se os princípios que reputamos valedouros produzem sobre o entendimento de outros indivíduos, escolhidos entre os mais hábeis, o mesmo effeito que produziram sobre o nosso, temos uma segurança mais de que esses 
princípios são verdadeiros. A apllicação desta regra philophica faz-se a todo momento, quando são citados pareceres de autores competentes para a corroborar a verdade de um facto ou theoria ou para apoio de uma interpretação.

Sobre a theoria da transmissão da febre amarella pelos mosquitos e a prophylaxia correlata, o consentimento universal dos autores tem sido até agora de uma unanimidade que impressiona, a quem quizer combate-la; o que é difficil é encoutrar na literatura médica autoridades que a contradigam (BOLETINS da SMCJF, 1904, p. 42).

O fragmento transcrito acentua a ideia de progresso, de adoção da "moderna ciência", explicitando que as medidas sugeridas para evitar a invasão e propagação do mal amarílico estavam pautadas nos referenciais da teoria havanesa. Na apresentação do plano, os redatores situaram e ressaltaram a importância da teoria culicidiana, destacando as pesquisas e descobertas pasteurianas, afirmando que as descobertas de Louis Pasteur teriam marcado uma fase de fecundas conquistas para a ciência (BOLETINS da SMCJF, 1904).

Após as considerações iniciais do relatório, foi iniciada a leitura das proposições formuladas pelos médicos Duarte de Abreu, Christovam Malta e José Nava5:

Syntheticamnete indica a comissão os meios que, se forem adoptados pelas municipalidades da Zona da Mata, em perfeita harmonia de vistas e de execução, livrarão o Estado de Minas do terrível hospede, que há ocorrido tão fortemente para a decadência de algumas cidades outrora prosperas.

a) Dessecar pelo aterro ou pela drenagem todos os pântanos, facilitar a canalisação das águas dentro da cidade (...) quando não for possível esse dessecamento será necessário tratar os pântanos e todas as aguas estagnadas por meio do petóleo ou da creolina em emulsão na água; (...)

b) Cada municipalidade deverá organizar um corpo de empregados de accordo com as suas necessidades, que se habilite para a boa execução dos serviços, podendo também desempenhar a funcção de enfermeiros;(...)

c) Cortar toda a vegetação dos brejos, não só para que o sol e os ventos, exercendo estes a acção de tiragem, melhor concorram para o seu dessecamento como também pela facilidade que decorrerá ao emprego do petróleo;

d)Velar no sentido de que as águas às margens dos rios e córregos não sejam embaraçadas em seu curso por meio de galhos de arvores frondosas ou de quasquer outros obstáculos;

e) Prohibir a collocação de fundos de garrafas nos muros; e nos quintaes, pateos e jardins, latas velhas, tinas ou quasquer outros objetos que possam servir de deposito às águas pluviaes, que proporcionariam ao mosquito fêmea um leito para a sua postura;

f) Verificar que os tanques destinados à lavagem da roupa funccionem bem e que tenham o orifício de descarga em um ponto de bastante declividade, de modo a lhes proporcionar completo escoamento para a rede de exgotos; quando aquelle trabalho domestico for feito nas tinas, estas deverão a ser emborcadas, terminado que seja, para assim não restar a menor quantidade d'água e sabão;

\footnotetext{
5 A longa transcrição se justifica pelo valor do documento ao argumento deste trabalho, e pela riqueza de detalhes apresentada no mesmo.
} 
g) Os tanques dos jardins públicos e particulares poderão ser conservados, desde que a água seja movimentada; si isto não acontecer, só serão permitidos si nelles houver peixes (...) para destruírem as larvas;

h) Trazer perfeitamente fechadas todas as caixas d'água, recommendando egual cuidado quanto aos moringues e a outros vasos de uso domestico, no tempo calmoso;

i) Adquirirem as municipalidades alguns exemplares dos dispositivos machanicos usados pela directoria de Saúde Publica do Rio de Janeiro, destinados às janelas, portas das casas particulares e do hospital de isolamento, para resguardar o doente nos quatro primeiros dias da moléstia contra o stegomya fasciata;

j) Publicar na imprensa local ou em boletins que serão largamente distribuídos pela população os conselhos decorrentes da doutrina havaneza, solicitar da classe medica a notificação de qualquer caso, ainda que levemente suspeito na quadra calmosa, como se fez com magnífico resultado em Havana;

k) Verificado duvidoso o diagnóstico, a auctoridade sanitária convidará outros collegas para examinarem o dente e prevalecerá a opinião que encontrar maior numero de defensores;

1) Confirmado o diagnostico de febre amarella, o doente será imediatamente isolado em domicilio, se dispõe de recursos para o tratamento; no caso negativo, será internado no hospital visando o isolamento exclusivamente em evitar, por meio da applicação dos dispositivos mechanicos que o mosquito sugue o sangue do amarellento durante o período enfectante da moléstia (quatro primeiros dias) e se habilite a propaga-la em tempo oportuno (12 a 18 dias) conforme a temperatura ambiente;

m) Far-se-á o expurgo do quarto em que tenha de ficar o doente por meio do pó de pyrethro ou de gaz sulfuroso, calafetando as fendas das portas e janellas, sacudindo as roupas, etc; só no fim de duas horas poderá o aposento ser ocupado pelo amarellento;

n) Installado o doente, proceder-se-á ao expurgo de toda casa infectada por meio daqueles agentes chimicos, principalmente nos pavimentos inferiores;

o) Operação egual deverá ser praticada nos prédios imediatos ao infectado e nos que lhe ficam fronteiros (BOLETINS da SMCJF, 1904: 49 - 52).

Conforme podemos verificar, a essência do plano consistia em destruir, por meios diretos e indiretos, o habitat do mosquito transmissor da febre amarela. Assim sendo, ressaltou-se práticas como o aterramento e drenagem dos pântanos para evitar a estagnação hídrica e a proibição de quaisquer objetos domésticos que pudessem armazenas águas pluviais (garrafas, latas, tanques de lavar roupa). Em relação às roupas, excretas e objetos utilizados por amarílicos não necessitavam passar por processo de desinfecção, visto não ser prudente por em dúvida a teoria atestada. Era necessário apenas depurar o ambiente no qual tenha se alojado o doente, através de gás sulfuroso, para matar larvas e o próprio mosquito transmissor da enfermidade.

Outra medida destacada era o isolamento do indivíduo infectado, com vistas a evitar, principalmente, a infecção do culicidio através do sangue do enfermo nos primeiros dias de manifestação da moléstia. Às autoridades sanitárias e profissionais de saúde em geral era 
dever proceder à notificação obrigatória dos casos constatados a fim de se obter maior controle da dimensão do mal e evitar sua disseminação. Ao final do relatório chamou-se a atenção das autoridades responsáveis para a reforma do serviço de higiene do Estado, de forma a se apresentar como uma organização harmônica e em consonância com os avanços médicos no controle de doenças.

As discussões sobre o relatório elaborado foram retomadas na sessão seguinte à da apresentação do mesmo, no dia 05 de março de 1904. O conteúdo do documento permaneceu inalterado, modificando-se, por solicitação do presidente Eduardo de Menezes, apenas a ordem dos meios propostos para evitar a propagação da febre amarela (BOLETINS da SMCJF, 1904). Na ocasião, foram questionadas quais seriam as bases seguras para a proposição e eficácia de tais medidas, uma vez que não estava, ainda, devidamente comprovado que o stegomya fasciata não poderia se contaminar em outro local senão o sangue dos amarílicos. Esse questionamento, na linha do que o médico Ambrósio Braga já havia levantado em momentos anteriores, ganhou peso nas defesas de alguns membros da associação. Em oposição a esse posicionamento, o médico Duarte de Abreu suscitou um debate destacando que, como a teoria culicidiana da transmissão da febre amarela já estava devidamente comprovada por pesquisas norte-americanas, e por testes brasileiros, no Rio de Janeiro e em São Paulo, esta não deveria ser questionada quando da proposição da medidas para conter a doença (BOLETINS da SMCJF, 1904).

Em seu discurso, Duarte de Abreu afirmou que “(...) ate há pouco, as medidas adoptadas eram complicadas, dispendiosas e vexatórias, porque andávamos às tontas, combatendo um inimigo absolutamente desconhecido" (BOLETINS da SMCJF, 1904, p. 56). O médico continuou ressaltando que diversas atitudes eram válidas e necessárias na luta contra a febre amarela, desde cuidados domésticos com estagnação de águas pluviais até a desinfecção de ambientes com o uso de enxofre. Assim, desde que o objetivo final fosse a destruição do culicidio e de suas larvas, as iniciativas de caráter pontual eram válidas (BOLETINS da SMCJF, 1904).

As discussões aqui abordadas nos mostram que, de forma geral, o perecer da comissão formada para elaborar o plano de defesa sanitária contra a febre amarela contou com a adesão e aceitação do corpo societário da instituição. A única divergência existente residiu sobre o exclusivismo da transmissibilidade da doença pelo stegomya fasciata, mas com pontuações de não questionamentos à validade da teoria havanesa.

Para os médicos da SMCJF a medicina pasteuriana dava fim às dificuldades oriundas da indeterminação etiológica que até o século XIX vigorou na atribuição das causas de 
doenças. Esta nova concepção possibilitava uma intervenção mais pontual da medicina frente às enfermidades. Para cada doença era reservada uma profilaxia específica, através de uma causa única. Era a ideia de "unicausalidade", relacionada à bacteriologia e aos "teóricos do germe", em contraponto à "multicausalidade", mais ligada aos fatores ambientais e higienistas. A higiene, no interior do discurso, era ressaltada enquanto a primeira das terapêuticas que, através dos meios preventivos, impedia a incursão de germes patogênicos no corpo humano. O intuito percebido na análise de todo o plano era de justificar e exaltar a teoria havanesa, nos moldes da bacteriologia, e afastar qualquer sombra de dúvidas sobre sua eficácia e, consequentemente, o efeito das medidas que estavam sendo propostas.

O relatório foi publicado na integra no jornal "O Pharol” do mesmo dia 03 de março, em que foi relido e aprovado pelos membros da SMCJF. A matéria foi intitulada de "Plano de Higiene Defensiva", e ocupou duas colunas da primeira página jornalística (Jornal O Pharol, 05/03/1904). De forma geral, todo o debate sobre o relatório foi acompanhado pelos cidadãos juizforanos que eram leitores do jornal. Como as atas da SMCJF estavam sendo publicadas no mesmo, foram dados ênfase e elogios à iniciativa da comunidade médica e aos "certeiros" benefícios que as medidas profiláticas trariam ao Estado de Minas em geral ${ }^{6}$.

A veiculação do plano elaborado pelos médicos para a sociedade em geral correspondeu aos anseios destes por evidenciar a importância de seu trabalho e a validade de seus conhecimentos específicos para o bem-estar da população. Ao acompanhar a discussão para elaboração do relatório e a constante preocupação dos médicos em evitar o acometimento de uma epidemia amarílica no município, os cidadãos tomariam conhecimento do trabalho executado na SMCJF e do interesse desta em prol da salubridade juizforana. E, concomitantemente, a mesma projeção das atividades médicas se faria sentir frente aos poderes públicos, demonstrando o interesse da instituição nos assuntos de caráter público, voltados para a melhoria das condições urbanas e de salubridade do município, marcando uma posição desses médicos no cenário social e político.

O plano de defesa contra a febre amarela foi enviado ao presidente do Estado de Minas, e o ofício que o acompanhou foi, também, publicado na imprensa local. Dentre as ressalvas dirigidas a Francisco Salles (presidente mineiro), destacamos o seguinte trecho: “A questão da prophylaxia da febre amarela foi objecto de longa discussão nesta Sociedade

\footnotetext{
${ }^{6}$ Ao ressaltar a ênfase dada pelo jornal às discussões e ao relatório em si, não podemos perder de vista que " $O$ Pharol" era de propriedade do Dr. Christovam Malta, que era membro da Sociedade. Assim sendo, o espaço conquistado pela SMCJF na imprensa juizforana, apesar de importante e de refletir o nome da Instituição, ocorreu, em grande medida, pelos próprios interesses do responsável pela veiculação das notícias.
} 
durante muitas sessões, e o relatório, depois de discutido, foi unanimente aprovado na sessão de 5 do corrente" (Jornal O Pharol, 29/03/1904).

As palavras acima ilustram a preocupação dos médicos com a validação científica da proposta, embasada nas discussões e conhecimentos técnicos desses profissionais. Outro ponto importante era a aprovação das medidas pelo corpo societário, sem que houvesse sérias contestações à mesma.

Não conseguimos documentos que demonstrassem se as informações e orientações do plano foram colocadas em prática. Todavia, a execução ou não das medidas propostas não consiste em peça fundamental para o argumento aqui desenvolvido. $\mathrm{O}$ que nos interessa não são as vitórias ou fracassos das posturas elaboradas pelos membros da Sociedade e sim as iniciativas da instituição em elaborar tais propostas, evidenciando tanto o papel da instituição enquanto "guarda avançada da salubridade pública", quanto o ideal de "ciência útil" que embasou os trabalhos da mesma. Além desses pontos, o destaque nesse texto se volta para as controvérsias em torno das formas de propagação da febre amarela, atentando para o peso da validação científica nos trabalhos desse grupo de médicos em fins do século XIX e início do XX, período de crescimento do ensino médico no país e busca de consolidação da profissão.

O estudo da elaboração do plano nos permite visualizar a atuação do corpo societário da SMCJF nas questões de saneamento da região como um todo. Ao tratar de uma doença específica, o corpo societário buscou, através do embasamento obtido pelas pesquisas e conhecimentos na área médica, demonstrar a importância das postulações da instituição para a salubridade local. Respaldados e justificados por um discurso científico que, por estar suficientemente comprovado, não era cabível de grandes contestações. Era a utilidade da ciência que, por intermédio do conhecimento e competência destes médicos, postulava regras e soluções para beneficiar a localidade em geral.

Diante da ameaça da invasão da febre amarela em Juiz de Fora, em virtude da proximidade da estação mais quente e dos casos que assolavam localidades vizinhas, urgia a necessidade de medidas enérgicas para conter e prevenir que a doença assolasse a população juizforana. Desta forma, a proposição do ataque aos culicidios ressaltava o interesse da Sociedade por questões de utilidade pública e, concomitantemente, o envio do projeto às autoridades ilustrava tal preocupação aos olhos das mesmas.

O reconhecimento do trabalho destes profissionais ultrapassou as fronteiras mineiras, o que pode ser verificado com a leitura, em sessão ordinária, de uma carta endereçada à Sociedade pelo então Diretor Geral de Saúde Pública, o já citado médico Oswaldo Cruz. Na 
correspondência, datada de 12 de outubro de 1904, Oswaldo Cruz prestava cumprimentos pelas

(...) brilhantes discussões travadas em seu seio [da SMCJF] e relativas à prophylaxia da febre amarella e pelas quais bem se pode avaliar do alto grao de cultura intellectual da classe medica de Juiz de Fora, que, longe de se achar affecta de misioneismo, caminha resoluta na vanguarda da sciencia que professamos (BOLETINS da SMCJF, 1904, p. 75).

O recebimento de tal correspondência engrandecia as iniciativas proferidas pelas SMCJF em consonância com os interesses de salubridade pública. E, paralelamente, como neste momento as sessões estavam sendo publicadas na imprensa local, a veiculação das atividades da instituição e o reconhecimento da importância da mesma pela sociedade em geral se processavam em maior demanda. A união do grupo em torno de um tema e objetivos comuns indicava tanto o pertencimento dos mesmos a um estrato específico da comunidade científica, como o interesse em ressaltar suas atividades para a sociedade em geral.

$\mathrm{O}$ aparente desacordo interno sobre as medidas a serem propostas às autoridades públicas esteve ligado, conforme pontuamos anteriormente, à forma de atuação frente a doença, e não sobre o papel do mosquito como vetor da febre amarela. Tal impasse, por sua vez, não indicava enfraquecimento dos laços corporativos, nem tampouco desqualificava o caráter associativo da Sociedade. Isto porque, segundo Bourdieu, independente do consenso ou não em relação aos trabalhos e postulações apontadas, é a unidade de questões que determina o pertencimento a uma geração de um campo intelectual (BOURDIEU, 1987).

Ainda segundo Bourdieu, os homens formados em uma determinada disciplina ou escola partilhariam de um espírito científico que lhes possibilitaria a comunicação imediata a despeito de seus conflitos e desacordos. E as questões nesse campo de trabalho, que compunham o repertório científico em voga, eram obrigatórias, possibilitando hegemonia ao campo (Idem). No nosso caso em análise, as epidemias de febre amarela nas cidades vizinhas e o temor da invasão da doença em Juiz de Fora, levaram os médicos a debaterem sobre o tema e apontarem caminhos para conter a enfermidade. Independente dos pontos conflitantes, a unidade de questões analisadas indicava o pertencimento destes médicos ao mesmo ambiente científico, e ressaltava os pontos característicos aos espaços associativos naquele contexto.

\section{Considerações finais}

Das enfermidades que estiveram em pauta nas discussões da SMCJF em suas primeiras décadas de atuação, a febre amarela suscitou um dos maiores debates nas seções da 
Sociedade. A discussão versou em torno da etiologia e propagação da doença, na justificativa dos médicos em organizar ações que impedissem que uma epidemia amarílica assolasse o município, como vinha ocorrendo com localidades vizinhas. O combate ao mal amarílico em Juiz de Fora fomentou o desenvolvimento de um plano de defesa sanitária remetido ao governo mineiro. Tal plano, contendo as medidas indicadas para conter a doença, evidenciava o trabalho do corpo societário em prol da salubridade urbana e condições de saúde locais e, concomitantemente, a força do associativismo, ressaltando a importância dos trabalhos desenvolvidos na instituição.

Em Juiz de Fora, as epidemias não foram as únicas responsáveis pelos projetos de saneamento e remodelamento urbano do município. Mas suscitaram, por sua vez, uma série de debates no círculo médico fomentando a elaboração de medidas que visassem controlar ou impedir o acometimento na cidade por ondas epidêmicas. No caso da febre amarela, o temor de um surto da doença em Juiz de Fora mobilizou discussões no seio da Sociedade, em consonância com os poderes públicos, gerando posturas de controle para novos surtos da enfermidade na cidade.

Em linhas gerias, era consenso entre os membros da SMCJF que a transmissão da doença se dava pelo mosquito, em conformidade com os ditames bacteriológicos. O que se discutiu amplamente nas seções da instituição foram as formas profiláticas a serem propostas para o controle e a proteção contra a doença. Uma parcela significativa dos membros reiterava que, conforme demonstrado pela teoria havanesa, a profilaxia consistiria primordialmente na caça aos mosquitos, com a desinfecção das casas e isolamento do doente aos ataques dos culicídios. Já para outra parcela, o ideal seria uma profilaxia mista, com atenção voltada às condições ambientais que poderiam favorecer o surgimento de novos insetos e a propagação da enfermidade.

Para além dos debates suscitados, o ponto a destacar é o propósito desses profissionais em afirmar a ciência que produziam e seu papel no cenário social e político do município. A elaboração de propostas de atuação nos espaços público e privado, como o plano de defesa contra febre amarela, foi uma das estratégias de defesa dos interesses corporativos. Essa era uma forma de evidenciar a utilidade e necessidade de seus conhecimentos específicos para a comunidade como um todo. Assim, a elaboração do plano de defesa contra a invasão da febre amarela em Juiz de Fora ratificava a preocupação destes médicos em ressaltar a importância de sua profissão e, de forma conjunta, a importância do associativismo e das atividades da Sociedade de Medicina e Cirurgia de Juiz de Fora para a municipalidade em geral e para os poderes públicos. 


\section{Referências Bibliográficas}

ACKERKNECHT, Erwin. Anticontagionism between 1821 and 1867. Bulletin of the History of Medicine, v.22, pp.562-593, 1948.

BENCHIMOL, Jaime (cord). Febre Amarela: a doença e a vacina, uma história inacabada. Rio de Janeiro: Fiocruz, 2001.

BENCHIMOL, Jaime. Dos micróbios aos mosquitos: Febre amarela e a revolução pasteuriana no Brasil. Rio de Janeiro: Fiocruz/UFRJ, 1999.

BOLETIM DA SMCJF - Ata da inauguração em 20 de outubro de 1889 - Discurso pronunciado pelo Dr. João Penido (Pai).

BOLETINS da Sociedade de Medicina e Cirurgia de Juiz de Fora. Juiz de Fora: Typ. de Obras d'O Pharol, 1904.

BOURDIEU, Pierre. A economia das trocas simbólicas. São Paulo: Ed. Perspectiva, 1987.

CAPEL, Horacio. El associativismo cientifico em iberoamerica. La necessidad de um enfoque globalizador. Interciencia, v.17, n.3, maio/junho, 1992, p.168-176.

CHRISTO. Maraliz Vieira. Europa dos Pobres, a belle-époque mineira. Juiz de Fora: EDUFJF, 1994.

CUNNIGHAM, Andrew; WILliAnS, Perry. The Laboratory Revolution in Medicine. Cambrige, 1992.

ESTATUTOS DA SMCJF - 1890 e 1906.

FERREIRA, Luiz Otávio; MAIO Marcos Chor e AZEVEDO, Nara. Sociedade de Medicina e Cirurgia do Rio de Janeiro: a gênese de uma rede institucional alternativa. História, Ciências, Saúde - Manguinhos, IV(3): 475-491, nov. 1997 - fev, 1998.

FIGUEIRÔA, Silvia Fernanda de Mendonça. As Ciências Geológicas no Brasil: uma história social e institucional, 1875-1934. São Paulo: HUCITEC, 1997.

GIROLETTI, D. Industrialização de Juiz de Fora: 1850/1930. Juiz de Fora: EDUFJF, 1988. JORNAL “O PHAROL” - 1888/ 1890-1897/ 1899-1908

LANA, Vanessa. Intercâmbio Científico: as relações Brasil - Alemanha através das lentes do colposcópio em meados do século XX. Caminhos da História, v.22, n.2, jul./dez. 2017.

LANA, Vanessa; TEIXEIRA, Luiz Antônio. Saúde, ciência e profissão médica em Minas Gerais: A Sociedade de Medicina e Cirurgia de Juiz de Fora (1889-1908). Cadernos de História da Ciência. Instituto Butantan. Vol. 4, N. 1, 2008, p. 07 - 38.

LANA, Vanessa. Uma associação científica no "interior das Gerais": a Sociedade de Medicina e Cirurgia de Juiz de Fora (SMCJF) 1889-1908. Dissertação de Mestrado. Casa de Oswaldo Cruz / Fundação Oswaldo Cruz; 2006.

MIRANDA, Sônia. Cidade, capital, poder: políticas públicas e questões urbanas na Velha Manchester Mineira. Dissertação de Mestrado. Universidade Federal Fluminense; 1990.

PELLING, Margaret. Contagion/ germ theory/ specificity. In: W.F. Bynun; Porter, Roy (ed). Companion Encyclopedia of the History of Medicine, vol.1, London e New York, Routledge, pp.309-334, 1993.

ROSEN, George. Uma História da Saúde Pública. São Paulo: HUCITEC/Abrasco, 1994.

TEIXEIRA, Luiz Antonio. Na Arena de Esculápio. A Sociedade de Medicina e Cirurgia de São Paulo (1895 - 1913). São Paulo: Editora Unesp, 2007.

TEIXEIRA, Luiz Antonio. Da transmissão hídrica à culicidiana: a febre amarela na Sociedade de Medicina e Cirurgia de São Paulo. Revista Brasileira de História, v. 1, n. 41, 2001.

VASCONCELOS, Pedro Fernando da Costa. Febre Amarela. Revista da Sociedade Brasileira de Medicina Tropical, 36(2):275-293, mar-abr, 2003.

VERSSURI, Hebe. Las asociaciones científicas Del siglo XIX en América Latina. Interciencia, v.17, n.3, maio/junho, pp.133, 1992. 